\title{
Coronary Artery Anomalies in Tetralogy of Fallot Patients Undergoing CT Angiography at a Tertiary Care Hospital
}

Tariq Ashraf ${ }^{1}$, Faiza Farooq ${ }^{2}$, Afaque Syed Muhammad ${ }^{1}$, Parveen Akhtar ${ }^{1}$, Mubashir Khan ${ }^{3}$, Amin M. Khuwaja $^{4}$, Muhammad N. Khan ${ }^{5}$, Musa Karim ${ }^{6}$

1. Cardiology, National Institute of Cardiovascular Diseases, Karachi, PAK 2. Adult Cardiology, National Institute of Cardiovascular Diseases, Karachi, PAK 3. Paediatric Cardiology, National Institute of Cardiovascular Diseases, Karachi, PAK 4. Anaesthesia and Intensive Care, National Institute of Cardiovascular Diseases, Karachi, PAK 5. Interventional Cardiology, National Institute of Cardiovascular Diseases, Karachi, PAK 6. Statistics, National Institute of Cardiovascular Diseases, Karachi, PAK

Corresponding author: Tariq Ashraf, tariqash45@gmail.com

\section{Abstract}

\section{Background}

The aim of this study was to determine the frequency of coronary artery anomalies (CAAs) in Tetralogy of Fallot (TOF) patients undergoing computed tomography (CT)-angiography in a tertiary care hospital.

\section{Methodology}

In this observational study, we included consecutive TOF patients undergoing CT-angiography without prior history of cardiac surgery or congenital heart disease. CAAs were defined based on either origin or course of the artery.

\section{Results}

Out of 441 TOF patients, the prevalence of CCAs was 3.6\% (16), of which 13 were below 18 years of age. Anomalous left main artery was observed in six (1.4\%) patients, followed by left anterior descending artery and right coronary artery, observed in four $(0.9 \%)$ patients each, and two $(0.5 \%)$ patients had a single coronary artery originating from the left coronary cusp with an interarterial course.

\section{Conclusions}

CAAs were observed in a significant number (3.6\%) of TOF patients. A CT-angiographic assessment before surgical correction would help identify the exact anatomy for better surgical planning to minimize complications.

Review began 09/12/2020 Review ended 09/28/2020 Published 09/29/2020

\section{() Copyright 2020}

Ashraf et al. This is an open access article distributed under the terms of the Creative Commons Attribution License CC-BY 4.0., which permits unrestricted use, distribution, and reproduction in any medium, provided the original author and source are credited.
Categories: Cardiac/Thoracic/Vascular Surgery, Cardiology

Keywords: coronary artery anomalies, ct angiography, tetralogy of fallot, tertiary care hospital

\section{Introduction}

Coronary artery anomalies (CAAs) are a complex group of congenital disorders that are highly variable in terms of clinical presentation and pathophysiological mechanisms and are not rare in congenital heart disease $[1,2]$. Tetralogy of Fallot (TOF) is the most common cyanotic congenital heart disease, accounting for 3.5 to $9 \%$ [3]. CAAs have been reported in 2 to $14 \%$ of TOF patients in coronary angiography, surgical and autopsy series [4]. In Pakistan, the true incidence of congenital heart disease is unknown due to limited access to medical care and limited resources to undertake intense population studies [5]. The reported incidence assessed by conventional angiogram is 5.6 to $8.4 \%$ [6]. Certain coronary anomalies are difficult to diagnose with TOF due to the complex anomalous origin and distribution of the coronary arteries [7]. These anomalies can add to morbidity and mortality during surgical repair [6]. The coronary anomalies of greatest concern are the origin of the left anterior descending coronary artery (LAD) from the right coronary artery (RCA) and certain variations of single coronary artery branching [2]. In order to improve surgical planning for better outcomes and to minimize the complications in tetralogy repair, effective imaging modalities are required to provide a thorough preoperative anatomic description of the associated intracardiac and extracardiac anomalies in TOF $[4,7]$. The identification of coronary anomalies can be documented by various techniques including autopsy, echocardiography, diagnostic coronary angiography, multislice coronary computed tomography (CT) angiography, or cardiac magnetic resonance imaging [8]. Of these, cardiac CT has particularly gained interest apart from echocardiography and MRI. Before the widespread use of coronary CT angiography, invasive catheter angiography was the standard for detecting CAAs [8]. Catheter angiography has obvious disadvantages, including its invasive nature and a small but finite risk of complications $[8,9]$. Coronary CT angiography is widely available and has proven to be an accurate and 
sensitive non-invasive alternative $[9,10]$. It provides excellent spatial resolution, fast acquisition time, no or little sedation, and an alternative to MRI in patients with pacemakers and implantable cardioverter defibrillators (ICDs) $[9,10]$. In the past, studies were conducted to assess CAAs in congenital heart diseases [11-14]. The current study assessed the incidence of coronary artery anomalies in patients with Tetralogy of Fallot by cardiac CT-angiography before total surgical correction in a cardiac tertiary care center.

\section{Materials And Methods}

This was an observational hospital-based study conducted at the National Institute of Cardiovascular Diseases (NICVD), Karachi. As per study inclusion criteria, 441 patients with Tetralogy of Fallot (TOF) who underwent cardiac CT-angiography were reviewed from the period of February 2012 to July 2017 with followup of two years. Exclusion criteria included patients who had undergone previous cardiac surgery and known forms of congenital heart diseases.

\section{Study oversight}

This study was approved by the Institutional ethics review committee (ERC) and conducted in compliance with Good Clinical Practice guidelines. The investigators agreed to maintain the confidentiality of the data. All the authors assure the completeness and accuracy of the data and data analyses.

\section{CT angiography}

All cardiac CT examinations were performed and interpreted by a consultant cardiologist with more than eight years of working experience. In all these patients CT examinations had been completed on a 64 slice dual-source scanner (SOMATOM Definition; Siemens, Germany) with the following scan parameters; 0.6 $\mathrm{mm}$ collimation, $80 \mathrm{kVp}$, and 30-80 mA with ECG dose modulation to minimize radiation exposure (typical dose of 5-8 mSv).

The scan coverage was from the brachiocephalic vessel to the upper abdomen. The contrast (ultravist 370) was injected through a peripheral intravenous catheter (18-20 gauge) at $4 \mathrm{ml} / \mathrm{sec}$ and with retrospective ECG gating via power injection. This was followed by a saline bolus. However each cardiac CT protocol varies slightly based on patient weight, associated lesions, prior surgical repair, and clinical questions asked at the time of examination. Scans were re-constructed with a slice thickness of $0.75-1.0 \mathrm{~mm}$ and a slice overlap of $0.6 \mathrm{~mm}$.

\section{Tetralogy of Fallot (TOF)}

Patients presenting with clinical suspicion of TOF such as cyanosis, clubbing, recurrent chest infections, and heart murmur underwent echocardiography and TOF was confirmed with echocardiographic findings of collective occurrence of four of the related heart defects, which included right ventricular (RV) outflow tract obstruction (RVOTO; infundibular stenosis), ventricular septal defect (VSD), overriding of aorta, and RV hypertrophy.

\section{Coronary artery anomalies (CAA)}

Coronary artery anomalies were defined based on either origin or course of the main coronary arteries such as left main (LM), left anterior descending coronary artery (LAD), left circumflex artery (LCX), and right coronary artery (RCA). The origin or course were considered normal as per the definition described elsewhere [15].

\section{Anomalous origin of coronary artery}

The coronary arteries can have variant anomalous origins and courses such as anomalous locations of coronary ostium within the proper coronary ostium but either high or low to ST junction or at commissural level, or there can be anomalous location of the coronary ostium outside the normal sinuses which can be either right posterior aortic sinus (RCC), ascending aorta, LV, RV, pulmonary artery, or from any other major coronary artery. Lastly there can be anomalous origin of coronary ositum from the opposite facing coronary sinus, RCA arising from left coronary cusp (LCC) with anomalous course, LAD arising from the RCC with anomalous course, LCX arising from RCC with anomalous course, and LM arising from RCC with anomalous course $[1,2]$.

\section{Anomalous course of coronary artery}

The anomalous coronary arteries originating from the improper sinus can take any of these courses: retrocardiac (posterior atrioventricular groove), retroaortic, preaortic (intratrial), intraseptal (supracristal), prepulmonary (precardiac), or posteroanterior interventricular groove $[1,2]$. The coronary artery anomalies in patients with Tetralogy of Fallot by cardiac CT-angiography are presented in Figure 1. 


\section{Cureus}

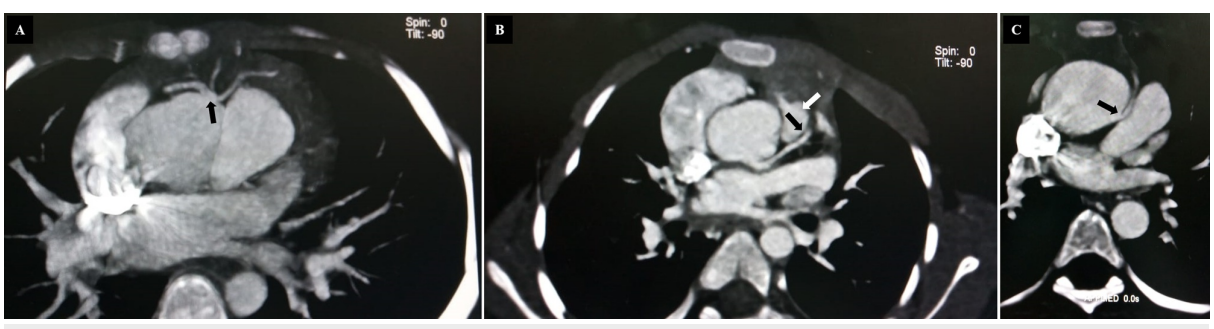

FIGURE 1: A) anomalous origin LAD from RCA, B) LAD passes close to pulmonic valve, and C) RCA originates from LCC with interarterial course.

$\mathrm{LAD}=$ left anterior descending coronary artery, RCA=right coronary artery, LCC=left coronary cusp

\section{Statistical analysis}

Statistical Package for the Social Sciences (SPSS ${ }^{\circledR}$ ) v21 (IBM Corp, Armonk, NY, USA) was used for the analysis of baseline characteristics. The frequency and percentages were calculated for categorical variables. The chi-square test was performed to evaluate the effect of age on study outcome. A two-sided p-value of less than 0.05 was taken as criteria for significance.

\section{Results}

\section{Baseline characteristics}

In this study, we reviewed cardiac CTs of 441 consecutive TOF patients, of which 257 (58.1\%) were male and the mean age was $11.66 \pm 9.14$ years. The majority $(80 \%)$ of the patients were under 18 years of age and the remaining $20 \%$ were up to 45 years. Demographic characteristics of the TOF patients are presented in Table 1.

\section{Characteristics}

$\mathrm{N}$

Gender

Male

Female

Age distribution

Range [maximum - minimum]

Mean \pm standard deviation

0 to 18 years

19 to 45 years

\section{Total}

441

$256(58 \%)$

$185(42 \%)$

1 month to 45 years

$11.66 \pm 9.15$

$354(80.3 \%)$

$87(19.7 \%)$

TABLE 1: Demographic characteristics of patients with Tetralogy of Fallot (TOF)

\section{Anomalous coronary arteries}

The prevalence of anomalous coronary arteries in TOF was found to be 3.6\% (16), of which 13 were observed in patients under 18 years and the remaining three cases were observed in patients 18 to 45 years. The incidence of anomalous coronary arteries by gender was $4.3 \%(11 / 256)$ vs. $2.7 \%(5 / 185)(\mathrm{p}=0.337)$ for male and female patients respectively.

\section{Anomalous left main}

The anomalous origin in the left main artery (LCA) was observed in six (1.4\%) patients, all between 0-18 years of age. Left main (LM) was found to be originated from right coronary cusp (RCC) in three patients, whereas for the other three patients, each had its origin from non-coronary cusp (NCC), pulmonary artery, 


\section{Cureus}

and sinotubular junction, respectively. Four of these anomalous originated left main arteries followed the normal course whereas for the remaining two, one covered the course through a retroaeortic route and one retropulmonic.

\section{Anomalous LAD}

The anomalous LAD was found in four patients out of which two arose from RCC and one from right coronary artery (RCA) whereas one had normal origin, i.e. left coronary cusp (LCC), but an anomalous course. In two of these patients, LAD followed an interarterial course, whereas it followed preaortic and retropulmonic courses in one patient each.

\section{Anomalous RCA}

The right coronary artery was anomalous in four patients, out of which two originated from NCC and from LCC and LAD in one patient each. The course of anomalous RCA was interarterial in two patients and retroaortic for the remaining two patients.

Two of the TOF patients had other anomalies such as single coronary artery from LCC with interarterial course. The most common course of anomalous coronary arteries was interarterial, often referred as the malignant course, comprised $37.5 \%$ (six out of 16 ), whereas the other $37.5 \%$ (six out of 16 ) appeared to be benign, consisting of retroaeortic in $18.8 \%$ (three out of 16), retropulmonic in $12.5 \%$ (two out of 16), and preaortic $6.3 \%$ (one out of 16 ) while four anomalous originated coronary artery followed the normal course and accounted for the remaining $25 \%$. The distribution of anomalous coronary arteries is presented in Table 2 .

\begin{tabular}{|c|c|c|c|c|}
\hline \multirow{2}{*}{ Characteristics } & \multirow{2}{*}{ Overall } & \multicolumn{2}{|l|}{ Age Groups } & \multirow{2}{*}{${ }^{* * P}$-value } \\
\hline & & 0 to 18 years & 18 to 45 years & \\
\hline $\mathrm{N}$ & 441 & 354 & 87 & - \\
\hline Anomalous Coronary Arteries & $16(3.6 \%)$ & $13(3.7 \%)$ & $3(3.4 \%)$ & 0.055 \\
\hline \multicolumn{5}{|l|}{ Left main (LM) coronary artery } \\
\hline Anomalous LM & $6(1.4 \%)$ & $6(1.7 \%)$ & $0(0 \%)$ & $0.036^{\star}$ \\
\hline \multicolumn{5}{|c|}{ Origin of Left Main [Base = LM Anomalous] } \\
\hline Non coronary cusp (NCC) & $1(16.7 \%)$ & $1(16.7 \%)$ & $0(0 \%)$ & \multirow{4}{*}{ - } \\
\hline Pulmonary artery & $1(16.7 \%)$ & $1(16.7 \%)$ & $0(0 \%)$ & \\
\hline Right coronary cusp (RCC) & $3(50 \%)$ & $3(50 \%)$ & $0(0 \%)$ & \\
\hline Sinotubular junction & $1(16.7 \%)$ & $1(16.7 \%)$ & $0(0 \%)$ & \\
\hline \multicolumn{5}{|c|}{ Course of Left Main [Base = LM Anomalous] } \\
\hline Normal & $4(66.7 \%)$ & $4(66.7 \%)$ & $0(0 \%)$ & \multirow{3}{*}{-} \\
\hline Retro-aortic & $1(16.7 \%)$ & $1(16.7 \%)$ & $0(0 \%)$ & \\
\hline Retropulmonic & $1(16.7 \%)$ & $1(16.7 \%)$ & $0(0 \%)$ & \\
\hline \multicolumn{5}{|c|}{ Left anterior descending coronary artery (LAD) } \\
\hline Anomalous LAD & $4(0.9 \%)$ & $3(0.8 \%)$ & $1(1.1 \%)$ & 0.49 \\
\hline \multicolumn{5}{|c|}{ Origin of LAD [Base = LAD Anomalous] } \\
\hline Left coronary cusp (LCC) & $1(25 \%)$ & 1 (33.3\%) & $0(0 \%)$ & \multirow{3}{*}{0.135} \\
\hline Right coronary artery (RCA) & $1(25 \%)$ & $0(0 \%)$ & $1(100 \%)$ & \\
\hline Right coronary cusp (RCC) & $2(50 \%)$ & $2(66.7 \%)$ & $0(0 \%)$ & \\
\hline \multicolumn{5}{|c|}{ Course of LAD [Base = LAD Anomalous] } \\
\hline Inter arterial & $2(50 \%)$ & $1(33.3 \%)$ & $1(100 \%)$ & \multirow{3}{*}{0.513} \\
\hline Preaortic & $1(25 \%)$ & $1(33.3 \%)$ & $0(0 \%)$ & \\
\hline Retropulmonic & $1(25 \%)$ & $1(33.3 \%)$ & $0(0 \%)$ & \\
\hline
\end{tabular}




\section{Cureus}

Right coronary artery (RCA)

Anomalous RCA

Origin of RCA [Base $=$ RCA Anomalous $]$

LAD

Left coronary cusp (LCC)

Non coronary cusp (NCC)

Course of RCA [Base $=$ RCA Anomalous $]$

Miscellaneous Coronary Anomalies

\section{TABLE 2: Distribution of Anomalous Coronary Arteries by Age Groups}

${ }^{*}$ Significant at $5 \%$

**p-values are based on chi-square test

The telephonic follow-up of the 16 TOF patients with CCAs was made after $18.56 \pm 6.43$ months and loss to follow-up rate was $43.8 \%$ (7). Loss to follow-up rate was higher due the fact that most of these patients belonged to the remote rural areas of Pakistan. Out of the remaining nine patients, three (33.3\%) of the patients underwent surgical correction and two $(22.2 \%)$ patients died. Of the patients who died, one patient, a boy aged nine months, underwent systemic-to-pulmonary artery (SP) shunt and cause of death was shunt blockage. For the other patient, a girl age eight months, no cardiac-related surgery was performed and she died of non-cardiac causes.

\section{Discussion}

The incidence of coronary abnormalities, i.e. CAAs, varies according to the method of detection applied by the investigators. Overall, in angiographic, surgical and autopsy series, coronary artery abnormalities have been reported in 2 to $14 \%$ of patients with TOF. Different studies have shown a low incidence of CAAs (2 to $5 \%$ ) during surgery because of difficulties in detecting the course and origin of vessels intraoperative as compared to autopsy findings that show a high incidence, i.e. 5 to $9 \%$. Assessment of the true incidence of CAAs is by cardiac CT angiography that helps to define the origin and course of the arteries in TOF, which is difficult or even impossible by invasive coronary angiography $[16,17]$.

American Heart Association and American College of Cardiology (ACC) guidelines recommend cardiac CT angiography as class I recommendation as a non-invasive method for diagnosis of CAAs [18]. Another noninvasive technique for defining CAAs is by magnetic resonance coronary angiography, which has the advantage over cardiac CT angiography of not using contrast agents or ionizing radiation [19]. The disadvantages over CT angiography are lengthy acquisition time, availability, and increased cost. CT angiography as compared to conventional invasive angiography gives a true outline of origin and course of CAAs.

The reported incidence of coronary anomalies in past angiographic studies was $7.0 \%$. The present study showed the overall incidence of coronary artery abnormalities with TOF in our population was $3.6 \%$, which corresponds to past studies data including Fellows et al. (84 patients, incidence 5\%) [20] and Dabizzi et al. (265 patients, incidence 9\%) [21]. This shows that coronary anomalies in TOF patients are present in a significant number and this indicates the importance of pre-operative coronary assessment by angiographic methods to manage the operative complications, including morbidity and mortality $[20,21]$.

In our study, the most common coronary artery anomaly was LM (1.4\%) followed by RCA and LAD $(0.9 \%)$ each and $0.5 \%$ gained anomalous origin as single coronary artery from left coronary cusp with interarterial course. The left main coronary artery anomaly is a rare congenital heart anomaly related to myocardial infarction (MI) and occurs in approximately one per 300,000 live births and represents $0.5 \%$ of all congenital heart defects [22]. Various studies have documented the most common CAAs to be LAD and LCX as a separate origin and incidence of $0.41 \%$ followed by LCX arising from the RCA with an incidence of $0.37 \%$ [2]. 
The course of CAAs has major clinical importance. Retroaortic, prepulmonic, and septal (subpulmonic) course anomalies appear benign, whereas LCA represents most commonly with a malignant course and carries a high risk for sudden cardiac death (SCD) [23,24]. Less frequently associated with SCD is RCA from left coronary sinus is more prevalent $(0.1 \%)$ [25]. In the present study, the most common course of anomalous coronary arteries was interarterial (37.5\%), whereas retroaeortic was $18.8 \%$ and the rest were retropulmonic (12.5\%) and preaortic (6.3\%). Four anomalous originated coronary artery followed the normal course and accounted for the remaining $25 \%$.

The existence of an anomalous course of coronary artery with TOF influences the choice of surgical strategy for complete repair. Inadvertent injury to an unrecognized coronary artery during repair is associated with poor outcomes [26]. The objective of surgery is adequate relief of RVOT obstruction with preservation of the coronary artery. Once the course of the anomalous coronary artery is delineated the surgical strategy is tailored according to the situation [27]. The immediate concerns are injury to the coronary artery resulting in myocardial ischemia, heart failure, or death [26] as well as RVOT obstruction because of inadequate relief limited by an anomalous coronary artery course [27]. In the long term, residual RVOT obstruction and reintervention are the concerns. The available surgical options are to do a staged repair with SP shunt as palliation; this approach may give a chance for improvement in the patient's physical health and the subsequent possibility for the use of RV and PA conduit, however this may not affect the natural history of disease [28], a combination of trans-atrial and trans pulmonary approach which may give best results despite the possibility of high RV/LV pressure ratio [27,29], use of an RV to PA conduit thus avoiding the area where the anomalous coronary artery is and finally translocation of the main pulmonary coronary artery [27]. Given the impact and anomalous coronary artery has on the conduct of surgery for TOF as well as the shortand long-term outcomes, it is imperative to identify the course of coronary arteries during evaluation of a patient for surgery, and with the increasing availability of a CT coronary angiogram it is possible to outline the exact course of both coronary arteries and plan the surgery accordingly.

Lost to follow-up of patients were more in their clinical course regarding their outcomes. Due to low incidence of CAA, reported statistical associations and p-values can be over- or underestimated.

\section{Conclusions}

The results of the present study demonstrate a 3.6\% incidence of TOF-associated coronary anomalies in a routine cardiac clinic. The coronary artery anomalies constitute a diverse group of abnormalities, ranging from anatomic variants to those having hemodynamic consequences. The assessment by cardiac CT-scan before surgical correction to identify the exact anatomy and known variation helps to improve surgical planning for better outcomes and minimize the complications by significantly reducing the morbidity and mortality during surgery.

\section{Additional Information \\ Disclosures}

Human subjects: Consent was obtained by all participants in this study. National Institute of Cardiovascular Diseases (NICVD), Karachi, Pakistan issued approval ERC-06/2017. This study was approved by the ethical review committee of the National Institute of Cardiovascular Diseases (NICVD), Karachi, Pakistan. Animal subjects: All authors have confirmed that this study did not involve animal subjects or tissue. Conflicts of interest: In compliance with the ICMJE uniform disclosure form, all authors declare the following: Payment/services info: All authors have declared that no financial support was received from any organization for the submitted work. Financial relationships: All authors have declared that they have no financial relationships at present or within the previous three years with any organizations that might have an interest in the submitted work. Other relationships: All authors have declared that there are no other relationships or activities that could appear to have influenced the submitted work.

\section{Acknowledgements}

The authors are thankful to all the doctors and staff members of the National Institute of Cardiovascular Disease, Karachi, for their support during the study. The authors are also thankful to Dr. Ali Yasir (The Searle Company Limited) for assistance in manuscript writing.

\section{References}

1. Angelini P: Coronary artery anomalies: an entity in search of an identity . Circulation. 2007, 115:1296-305. 10.1161/CIRCULATIONAHA.106.618082

2. Villa AD, Sammut E, Nair A, Rajani R, Bonamini R, Chiribiri A: Coronary artery anomalies overview: The normal and the abnormal. World J Radiol. 2016, 8:537-55. 10.4329/wjr.v8.i6.537

3. Bailliard F, Anderson RH: Tetralogy Of Fallot. Orphanet J Rare Dis. 2009, 4:2. 10.1186/1750-1172-4-2

4. Giordano R, Cantinotti M, Di Tommaso L, Palma G: Surgical strategy for tetralogy of Fallot with abnormal coronary arteries. J Thorac Dis. 2017, 9:3447-9. 10.21037/jtd.2017.09.113

5. Humayun KN, Atiq M: Clinical profile and outcome of cyanotic congenital heart disease in neonates . J Coll Physicians Surg Pak. 2008, 18:290-3.

6. Hussain I, Patel N, Ghaffar A, Kundi A: Coronary anomalies in Pakistani children with tetralogy of Fallot . J 
Coll Physicians Surg Pak. 2010, 20:3-5.

7. Tuzcu EM, Moodie DS, Chambers IL, Keyser P, Hobbs RE: Congenital heart diseases associated with coronary artery anomalies. Cleve Clin J Med. 1990, 57:147-52. 10.3949/ccjm.57.2.147

8. Holst KA, Said SM, Nelson TJ, Cannon BC, Dearani JA: Current interventional and surgical management of congenital heart disease: specific focus on valvular disease and cardiac arrhythmias. Circ Res. 2017, 120:1027-44. 10.1161/CIRCRESAHA.117.309186

9. Sun ZH, Liu YP, Zhou DJ, Qi Y: Use of coronary CT angiography in the diagnosis of patients with suspected coronary artery disease: findings and clinical indications. J Geriatr Cardiol. 2012, 9:115-22. 10.3724/SP.J.1263.2012.01041

10. Wilson GT, Gopalakrishnan P, Tak T: Noninvasive cardiac imaging with computed tomography . Clin Med Res. 2007, 5:165-71.10.3121/cmr.2007.747

11. Hussain I, Zeb S, Irfan M, Ali U: Spectrum of congenital cyanotic heart disease in Khyber Pakhtoonkhwa . Pak Heart J. 2016, 48:190-3.

12. Pathan IH, Bangash SK, Khawaja AM: Spectrum of heart defects in children presenting for paediaric cardiac surgery. Pak Heart J. 2016, 49:29-32.

13. Saeed S, Hyder SN, Sadiq M: Anatomical variations of pulmonary artery and associated cardiac defects in tetralogy of Fallot. J Coll Physicians Surg Pak. 2009, 19:211-4.

14. Wazir AS, Younas M, Beg A, Chawdry TA, Sadiq N: Pulmonary artery variants and associated cardiac defects in tetralogy of Fallot. J Postgrad Med Inst. 2017, 31:339-42.

15. Coronary Artery Anomalies. (2018). Accessed: 25 August 2019: https://emedicine.medscape.com/article/895854-overview.

16. Adamson PD, Newby DE: Non-invasive imaging of the coronary arteries. Eur Heart J. 2018, 40:2444-54. 10.1093/eurheartj/ehy670

17. Gräni C, Buechel RR, Kaufmann PA, Kwong RY: Multimodality imaging in individuals with anomalous coronary arteries. JACC Cardiovasc Imaging. 2017, 10:471-81. 10.1016/i.jcmg.2017.02.004

18. Warnes CA, Williams RG, Bashore TM, et al.: ACC/AHA 2008 guidelines for the management of adults with congenital heart disease: a report of the American College of Cardiology/American Heart Association Task Force on Practice Guidelines (Writing Committee to Develop Guidelines on the Management of Adults With Congenital Heart Disease). Developed in Collaboration With the American Society of Echocardiography, Heart Rhythm Society, International Society for Adult Congenital Heart Disease, Society for Cardiovascular Angiography and Interventions, and Society of Thoracic Surgeons. J Am Coll Cardiol. 2018, 52:143-263. 10.1016/j.jacc.2008.10.001

19. McConnell MV, Ganz P, Selwyn AP, Li W, Edelman RR, Manning WJ: Identification of anomalous coronary arteries and their anatomic course by magnetic resonance coronary angiography. Circulation. 1995, 92:3158-62. 10.1161/01.cir.92.11.3158

20. Fellows KE, Freed MD, Keane JF, Praagh R, Bernhard WF, Castaneda AC: Results of routine preoperative coronary angiography in tetralogy of Fallot. Circulation. 1975, 51:561-6. 10.1161/01.cir.51.3.561

21. Dabizzi RP, Caprioli GI, Aiazzi LU, Castelli CA, Baldrighi GI, Parenzan LU, Baldrighi VI: Distribution and anomalies of coronary arteries in tetralogy of fallot. Circulation. 1980, 61:95-102. 10.1161/01.cir.61.1.95

22. Keith JD: The anomalous origin of the left coronary artery from the pulmonary artery . Br Heart J. 1959, 21:149-61. 10.1136/hrt.21.2.149

23. Charan L, Shiradkar S, Kerkar PG, Ashish A: Stenting of anomalous left main coronary artery stenosis in an adult with a retroaortic course. Cardiol Res Pract. 2011, 2011:296946. 10.4061/2011/296946

24. Narayanan MA, DeZorzi C, Akinapelli A, Haddad TM, Smer A, Baskaran J, Biddle WP: Malignant course of anomalous left coronary artery causing sudden cardiac arrest. A case report and review of the literature. Case Rep Cardiol. 2015, 2015:806291. 10.1155/2015/806291

25. Camarda J, Berger S: Coronary artery abnormalities and sudden cardiac death. Pediatr Cardiol. 2012, 33:4348. 10.1007/s00246-012-0168-0

26. Humes RA, Driscoll DJ, Danielson GK, Puga FJ: Tetralogy of Fallot with anomalous origin of left anterior descending coronary artery. Surgical options. J Thorac Cardiovasc Surg. 1987, 94:784-7.

27. Kalfa DM, Serraf AE, Ly M, Le Bret E, Roussin R, Belli E: Tetralogy of Fallot with an abnormal coronary artery: surgical options and prognostic factors. Eur J Cardiothorac Surg. 2012, 42:34-9. 10.1093/ejcts/ezs367

28. Lindberg HL, Saatvedt K, Seem E, Hoel T, Birkeland S: Single-center 50 years' experience with surgical management of tetralogy of Fallot. Eur J Cardiothorac Surg. 2011, 40:538-42. 10.1016/..ejcts.2010.12.065

29. Need LR, Powell AJ, del Nido P, Geva T: Coronary echocardiography in tetralogy of Fallot: diagnostic accuracy, resource utilization and surgical implications over 13 years. J Am Coll Cardiol. 2000, 36:1371-7. 10.1016/50735-1097(00)00862-7 